\title{
EDUCAÇÃO AMBIENTAL
}

\section{EDUCAÇÃO AMBIENTAL SOBRE A RELEVÂNCIA DA ÁGUA NAS AÇÕES COTIDIANAS: UMA ESTRATÉGIA PARA CONSCIENTIZAÇÃO AMBIENTAL DE ALUNOS DA ESCOLA MUNICIPAL TENDA DOS MORENOS, UBERLÂNDIA-MG}

\author{
Ingrid da Silva Pacheco - ingrid_1194@ hotmail.com \\ Universidade Federal de Uberlândia \\ Maraína Souza Medeiros - maraliss@ @otmail.com \\ Universidade Federal de Uberlândia \\ Edyane Tássia Padilha- edyanetassia@ hotmail.com \\ Universidade Federal de Uberlândia \\ Layla Giovanna Girotto - laylagg.eab@ gmail.com \\ Universidade Federal de Uberlândia
}

Andressa Costa e Silva Cabral - andressaa_cabral@hotmail.com

Universidade Federal de Uberlândia

Luiz Fernando Ribeiro Araújo - luiz_ribeiro07@ hotmail.com

Universidade Federal de Uberlândia

Fábio Augusto do Amaral - fabioamaral @yahoo.com.br

Universidade Federal de Uberlândia

Sheila Cristina Canobre - scanobre@yahoo.com.br

Universidade Federal de Uberlândia

Resumo: A água tem papel fundamental na existência de vida em todo o planeta terra. Ademais, é de vital importância para setores como de produção agrícola e industrial. Embora seja reconhecida sua importância, há vários impactos ambientais sobre a água oriundos de ações antrópicas, tais como: contaminação pelo despejo inadequado de efluentes; escoamento superficial agrícola, escoamento superficial urbano, bem como proliferação de doenças pela ingestão de água de má qualidade. Crianças que frequentam unidades escolares na zona rural estão mais suscetíveis a doenças infecciosas devido à qualidade inadequada da água de consumo oferecida. Pensando nisso, o presente trabalho buscou abordar o tema "Água: importância, contaminação e reuso", mediante minicursos oferecidos sobre Educação Ambiental (EA), na Escola Municipal Tenda dos Morenos, localizada na região de Uberlândia-MG. Foram propostas atividades educativas para as turmas de $4^{\circ}$ ao $9^{\circ}$ ano ressaltando aspectos da importância e escassez da água, bem como a contaminação e doenças de veiculação hídrica. Cada atividade proposta foi pensada conforme a idade escolar dos respectivos alunos. Os resultados alcançados apontaram para uma melhor conscientização dos alunos quanto à importância ambiental desse recurso, além de mostrar a preocupação dos mesmos sobre a possível escassez de água devido ao desperdício nas atividades do cotidiano e a falta de conscientização quanto ao reuso. 

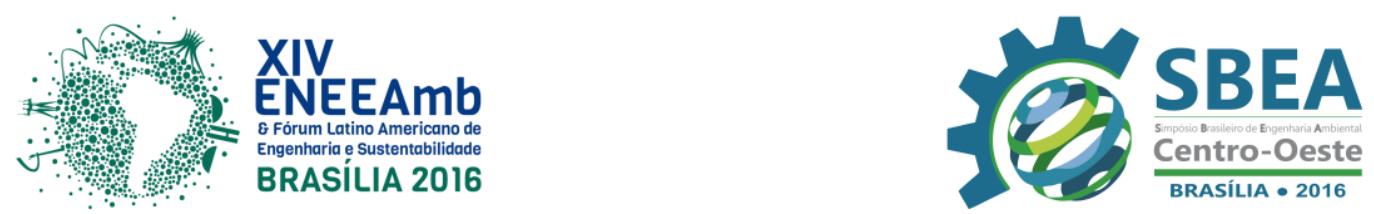

Palavras-chave: Águas, Educação Ambiental, Ensino Fundamental.

\section{INTRODUÇÃO E OBJETIVOS}

O recurso água, em especial, tem sua importância reconhecida para hidratação e higienização dos seres humanos, na sobrevivência de animais e plantas, na produção de alimentos, no desenvolvimento industrial e outros. No entanto, problemas de ordem ambiental são cada vez mais evidentes com relação a esse recurso, o aporte de poluentes em águas superficiais e subterrâneas, por exemplo, é uma forma de contaminação desse recurso hídrico que compromete sua qualidade, principalmente pelo despejo de efluentes doméstico e industrial, escoamento superficial urbano e escoamento superficial agrícola. Todas essas formas de contaminação apontam para a necessidade de mudança no comportamento humano frente ao uso da água (GRASSI, 2001).

Assim, com a crescente contaminação do meio ambiente e a preocupação do homem em solucioná-la, surgiram, nos últimos cinquenta anos, várias discussões em todo o mundo sobre a Educação Ambiental (EA) em eventos de cunho social e político. Ademais, dessas discussões resultaram em documentos educacionais como ferramentas de combater a crise ambiental que assola o planeta terra, bem como posicionamento de ambientalistas acerca dessa situação (FREITAS \& MARIN, 2015).

A Educação Ambiental, conforme relatos de Cuba (2010) trata-se da adoção da gestão ambiental como princípio educativo do currículo escolar, bem como da centralização da ideia de participação dos indivíduos na gestão de diversos lugares, tais como: escola, rua, bairro, cidade e outros. Enfim, o propósito inicial da EA é de exatamente servir como apoio para que as pessoas adotem uma nova postura com relação ao seu próprio lugar, em função dos impactos ambientais sofridos pela população mundial.

Os Parâmetros Curriculares Nacionais para o Ensino Fundamental (BRASIL, 1997)

propõe que ao considerar a importância da temática ambiental e a visão integrada de mundo, a escola deverá basicamente, ao longo dos oitos anos do Ensino Fundamental, trabalhar o conhecimento e a compreensão dos alunos de forma sistêmica e integrada, de conceitos essenciais relacionados ao meio ambiente. Ademais, estimular novas posturas dos educandos ambientalmente sustentáveis tanto na escola quanto na comunidade.

Considerando a importância da água para o mundo e os impactos ambientais oriundos das ações antrópicas, este trabalho teve como objetivo trabalhar a Educação Ambiental aliada à temática "água" no intuito de conscientizar os alunos da Escola Municipal Tenda dos Morenos (zona rural de Uberlândia-MG) a respeito de alguns assuntos: importância e escassez da água e contaminação e doenças de veiculação hídrica.

\section{METODOLOGIA}

Os minicursos oferecidos sobre Educação Ambiental cujo tema foi “Água: importância, contaminação e reuso" foram realizados com enfoque aos alunos do $4^{\circ}$ ao $9^{\circ}$ ano do Ensino Fundamental da Escola Municipal Tenda dos Morenos, localizada na região de Uberlândia-MG. O público alvo era composto de 105 estudantes, cuja faixa etária variava de 

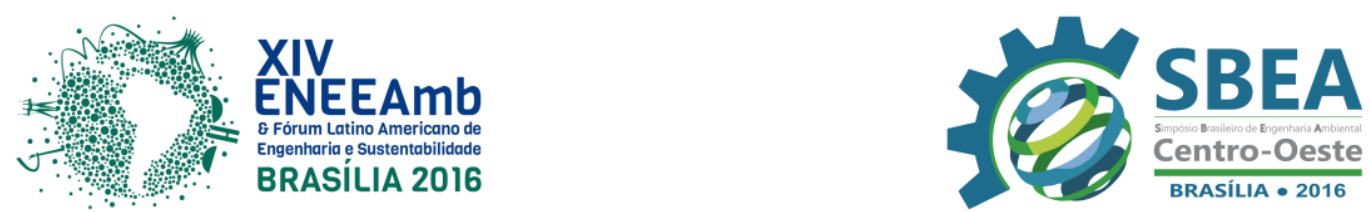

10 a 17 anos. Antes da realização das atividades, foi explicado aos alunos o intuito do projeto, bem como dos integrantes responsáveis pela sua execução.

Os minicursos oferecidos sobre Educação Ambiental propostos foram planejados pelos integrantes da pesquisa através de leituras de literaturas da área (e. g. artigos científicos sobre qualidade da água, importância e escassez, doenças de veiculação hídrica e contaminação/poluição de corpos d'água, além de atividades educativas para cada idade escolar mediante a temática água). Para a execução das atividades na referida unidade escolar, foram utilizados slides projetados em uma sala de informática (midiateca), bem como a utilização de uma atividade prática, a qual consistia em verificar as características da água (incolor, insípida e inodora) a partir de um experimento com três erlenmeyers contendo três tipos de água em cada frasco, o primeiro com solo vermelho (com coloração), o segundo com a substância química vinagre (com cheiro) e o terceiro apenas com água potável, então três alunos voluntários realizaram testes visuais e sensoriais das amostras de água citadas anteriormente, em seguida foi explicado que mesmo a água estando transparente é necessário verificar outras características para que essa esteja própria para consumo.

Os assuntos relacionados ao tema ambiental em questão foram divididos em dois grandes temas, sendo eles: importância da água e sua escassez e; contaminação dos recursos hídricos e doenças vinculadas a água, mostrados na Figura 1. Os dois temas foram trabalhados com as turmas de $4^{\circ}$ ao $9^{\circ}$ ano do Ensino Fundamental, sendo o minicurso dividido da seguinte forma: uma aula de cinquenta minutos para o $4^{\circ}$ ano; uma aula de cinquenta minutos para o $5^{\circ}$ e $6^{\circ}$ anos em conjunto; uma aula de cinquenta minutos para o $7^{\circ}$ ano e; uma aula de cinquenta minutos para $8^{\circ}$ e $9^{\circ}$ anos em conjunto, com autorização da direção escolar. Essas aulas foram compostas de atividades distintas, as quais podem ser visualizadas na Figura 1. Após a aula, foram entregues lembrancinhas com o intuito de estender a conscientização ambiental aos familiares dos alunos ao notarem a presença da lembrancinha nas mochilas dos (as) filhos (as).

\begin{tabular}{|c|c|c|}
\hline $\begin{array}{c}\text { Parte 1: Importância da água e } \\
\text { Escassez }\end{array}$ & $\begin{array}{c}\text { Parte 2: contaminação dos recursos } \\
\text { hídricos e doenças vinculadas a água }\end{array}$ \\
$\begin{array}{c}\text { exposição dialogada do conteúdo proposto } \\
\text { sobre a temática da parte 1 com a projeção } \\
\text { de slides e video. }\end{array}$ & $\begin{array}{c}\text { exposição dialogada do conteúdo proposto } \\
\text { sobre a temática da parte 2 com a projeção } \\
\text { de slides e video. }\end{array}$ \\
$\begin{array}{c}\text { Atividade 1: atividade lúdica sobre o } \\
\text { conteúdo ensinado, utilizando um mini- } \\
\text { jogo de perguntas e respostas e uma } \\
\text { questão discursiva. }\end{array}$ & $\begin{array}{c}\text { Atividade 2: experimento prático sobre as } \\
\text { caracterísicas organolépticas das água. }\end{array}$ \\
\hline
\end{tabular}

Figura 1 - Fluxograma representando os temas trabalhados durante os minicursos ministrados aos alunos do $4^{\circ}$ ao $9^{\circ}$ ano em relação a ações de educação ambiental, na Escola Municipal

Tenda dos Morenos, Uberlândia - MG. 

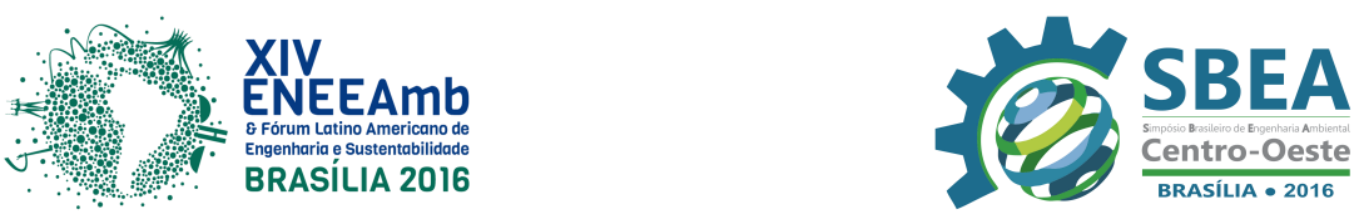

\section{RESULTADOS E DISCUSSÕES}

\subsection{Palestra para as turmas de $4^{\circ}$ e $5^{\circ}$ Ano}

$\mathrm{Na}$ aula desenvolvida conjuntamente com as turmas do $4^{\circ}$ e $5^{\circ}$ anos, notou-se que os alunos possuíam bastante interesse sobre o tema, sendo que ao perguntar sobre a utilização da água para a produção de energia elétrica em hidrelétricas, um dos alunos soube explicar de forma simples e correta como acontece todo o processo, deixando as palestrantes surpresas. Ele mencionou que a água é represada, e que quando ela chega à turbina ocorre à transformação da energia pelo movimento das hélices, gerando, assim, energia elétrica.

Após a correção da folha de respostas de cada um dos alunos, na atividade de perguntas e respostas, foi possível identificar quatro ganhadores que conseguiram acertar as cinco questões de múltipla escolha, bem como as duas perguntas discursivas. Estes quatro alunos foram premiados com uma pequena lembrancinha como reforço positivo da importância da água e também uma maneira alternativa de tornar a aula mais atrativa. As quatro melhores respostas relatavam que as principais atividades que nós seres humanos devemos praticar diariamente para economizar a água são: fechar a torneira enquanto escovamos os dentes; não tomar banhos demorados; não lavar o carro com mangueira e; não deixar a torneira aberta. Quanto às questões discursivas sobre o fato de água potável no mundo acabar ou não no futuro, pode-se observar que conforme os dados apontados na Figura 2, em uma turma composta de 32 alunos ( $4^{\circ}$ e $5^{\circ}$ anos), a maioria acredita que água um dia pode acabar ( $91 \%$ das crianças). Isso mostra que os alunos percebem que ações que contaminam, poluem e tornam a água escassa pode ocasionar na sua falta em um futuro não tão distante. Em contrapartida, 6\% dos alunos disseram "talvez" para a questão, alguns dos alunos justificaram a resposta dizendo que depende das ações do homem o fato dela acabar ou não.

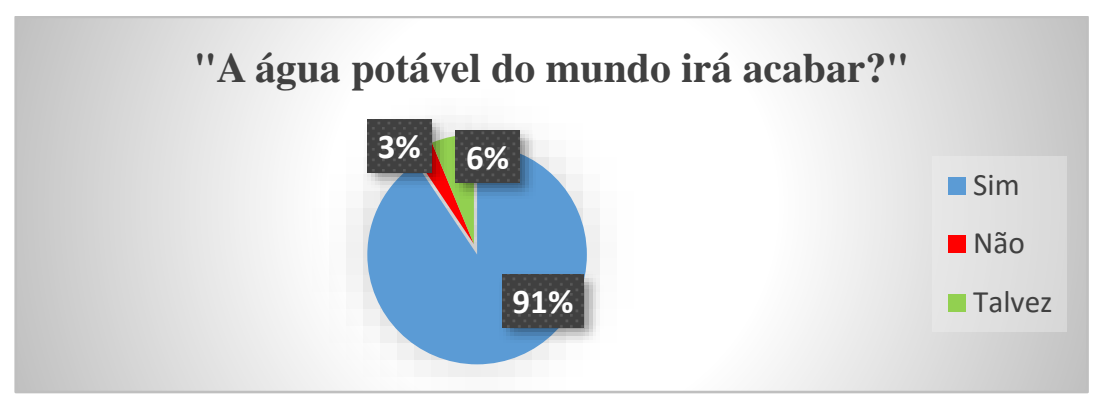

Figura 2 - Percentual das respostas dos 32 estudantes a pergunta "A água potável no mundo irá acabar?", na Escola Municipal Tenda dos Morenos, turma de $4^{\circ}$ e $5^{\circ}$ anos.

\subsection{Palestra para a turma de $6^{\circ}$ ano}

Na primeira da palestra, iniciou-se as atividades abordando sobre a importância da água e quando foi perguntando aos alunos "Para que a água é importante?", com o intuito de ver o interesse e participação dos estudantes com o tema, obteve-se respostas coerentes, como: para os animais, para as plantas, para lavar vasilha, para tomar banho, escovar os dentes, para beber, dentre outras. Tais respostas mostram que os alunos do $6^{\circ}$ Ano não enxergam a água somente para fins pessoais (hidratação e higiene pessoal), mas também como um recurso importante para todos os seres vivos. 

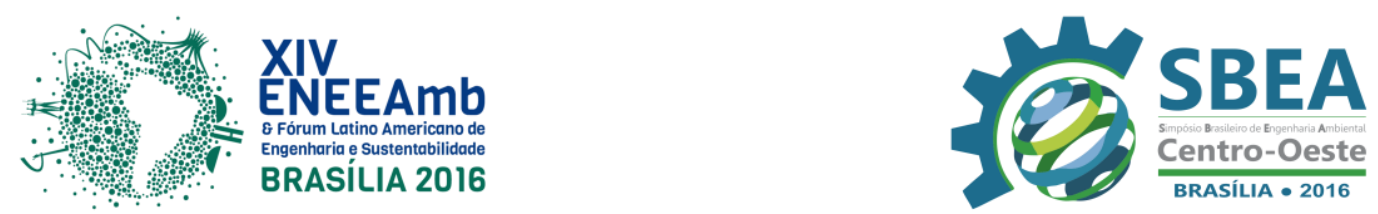

Para conhecer sobre a origem da água que chega à casa dos alunos foi perguntado a eles de qual local vinha a água que eles consomem em casa (Poço artesiano, mina d'água, DMAE). Dessa forma, notou-se que cerca de $40 \%$ da turma adquire a água por meio de poço artesiano, o que se explica pelo fato de residirem na zona rural, na Figura 3 pode-se visualizar a exposição do conteúdo para os alunos do $6^{\circ}$ ano.

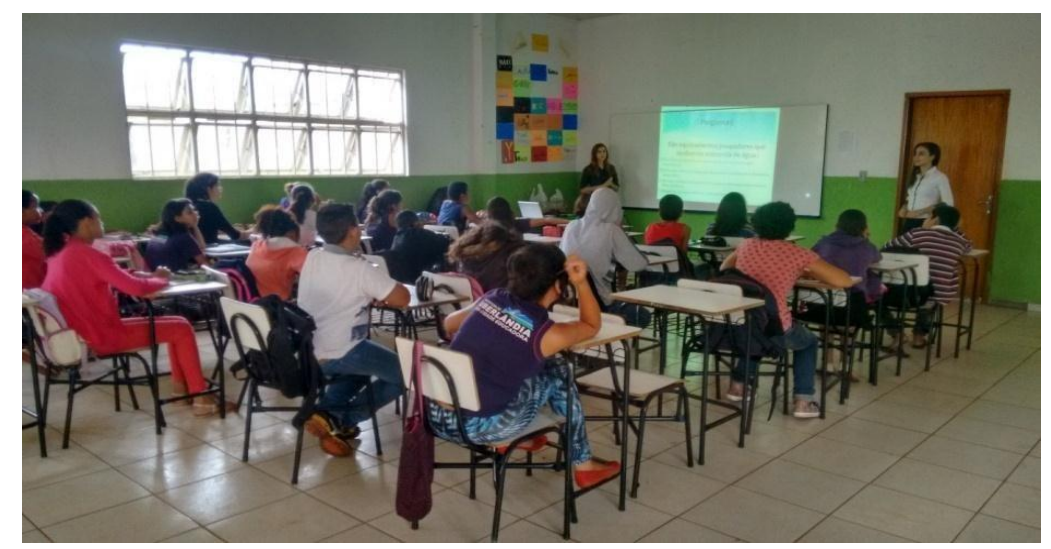

Figura 3 - Alunos do $6^{\circ}$ ano da E.M. Tenda dos Morenos atentos ao conteúdo exposto pelas palestrantes sobre o tema da importância da água.

Na sequência sobre a explicação da importância da água, indagou-se os alunos quanto a quantidade diária ideal de ingestão de água pelo ser humano para fins de manutenção da saúde. Muitos alunos conseguiram responder que são dois litros de água, demonstrando conhecimento aprofundado sobre esse assunto.

Em um dos momentos, as palestrantes fizeram uma pesquisa com os alunos realizando uma série de perguntas, tais como: "Quem demora muito no banho", "Quem deixa torneira ligada ao lavar as louças", "Os pais lavam o carro com mangueira?", "Quem fecha a torneira ao escovar os dentes?", notou-se que cerca de $50 \%$ da turma possui a consciência sobre o desperdício, mas que não estavam sensibilizados com a causa. Dessa forma, após ser mostrado o infográfico com a relação de gastos de água, eles se demonstraram bastantes surpreendidos com a quantidade de água que se gasta para fazer atividades cotidianas.

Uma observação importante que foi notada é o fato de que os alunos não sabiam o que era a palavra "escassez", e ficaram curiosos para saber do que se tratava. Dessa forma, ao mostrar imagens de rios secos e com falta de água, notou-se que os estudantes compreenderam o significado desse conceito.

$\mathrm{Na}$ atividade de perguntas e respostas, um aluno foi premiado com o maior número de acertos das questões, respondendo que acredita que a água potável no mundo irá acabar e citando como uma das medidas para economia de água é o fechamento da torneira ao escovar os dentes. Ademais, obtiveram-se outras respostas relevantes, para a questão do esgotamento da água potável, no sentido de que se as pessoas não cuidarem da água ou não pararem de desperdiça-la em suas ações cotidianas ela irá acabar sim.

Nessa turma de 27 alunos do $6^{\circ}$ ano, $30 \%$ acredita que a água no mundo não irá acabar, $63 \%$ acreditam que sim, e $7 \%$ acham que talvez, os dados podem ser visualizados na Figura 4. 


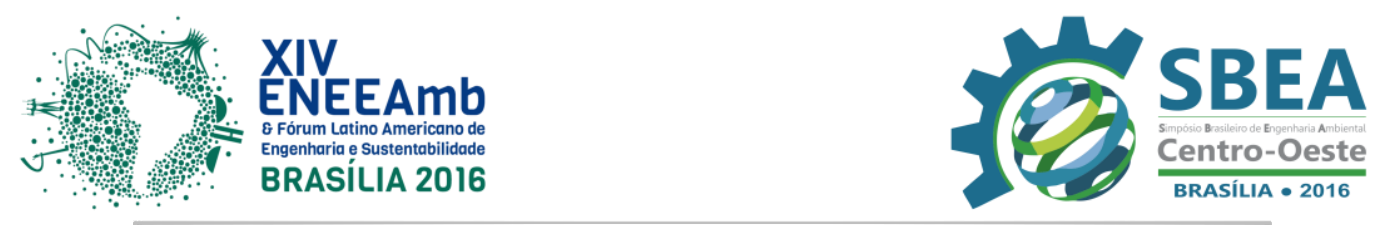

"A água potável no mundo irá acabar?"

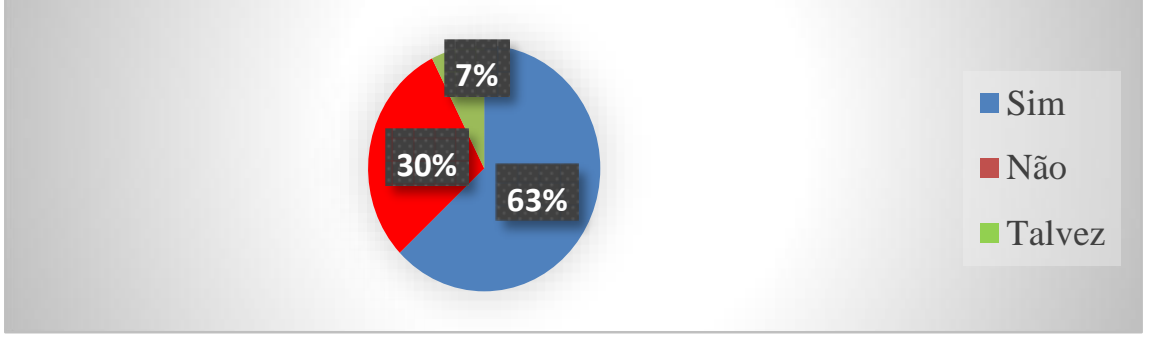

Figura 4 - Percentual das respostas dos 27 estudantes a pergunta “A água potável no mundo irá acabar?", na Escola Municipal Tenda dos Morenos, turma de $6^{\circ}$ ano.

No segundo momento da aula, apresentou-se o tema de doenças e contaminação da água. Introduziu-se o tema com um dos graves problemas que o Brasil está enfrentando, a dengue. Observou-se que na escola havia murais com atividades que os alunos fizeram sobre o tema, sendo assim, eles já tinham um conhecimento prévio sobre o assunto. Notou-se que muitos estudantes sabiam o nome do mosquito e suas características, como as manchas brancas.

$\mathrm{Na}$ atividade prática, as palestrantes perguntaram se a água com coloração escura, a com terra, poderia ser consumida, e todos responderam que não, justamente devido à cor. Ao perguntar sobre a segunda amostra, os estudantes disseram que ela poderia ser consumida, mas ao pedir para a voluntária sentir o cheiro da água, eles entenderam que não é só o fato da cor que deve ser levado em consideração, os alunos fizeram caretas ao sentirem o odor da amostra de água contendo vinagre. Mediante tais relatos, as palestrantes explicaram aos alunos que a água apresenta três características fundamentais: incolor, inodora e insípida, ou seja, a água que utilizamos para a nossa ingestão diária não pode conter cheiro, gosto e nem aspecto visual escuro, pois se alguma dessas características não for respeitada significa que esse recurso hídrico apresenta algum tipo de contaminação e/ou poluição.

\subsection{Palestra para a turma de $7^{\circ}$ ano}

$\mathrm{Na}$ turma de $7^{\circ}$ ano, dentre os questionamentos realizados, um que chamou bastante a atenção das palestrantes foi à pergunta de um aluno quanto ao armazenamento de água. O aluno perguntou se ele armazenasse a água em uma garrafa PET por 10 anos se ele poderia consumi-la após esse período. Pelo seu questionamento, pode-se perceber sua preocupação com a possível falta desse recurso futuramente, mostrando que ele já pensa em uma forma de armazenar a água para consumi-la caso falte. Durante a discussão sobre desperdício da água foi notável a consciência dos alunos quanto a atividades como escovar os dentes com a torneira fechada, lavar a louça com a torneira fechada também, não lavar o carro com a mangueira aberta o tempo todo (mesmo alguns relatando que os pais têm essa postura), usar regador para regar as plantas, dentre outros.

$\mathrm{Na}$ atividade de perguntas e respostas, três alunos foram premiados pelo bom desempenho na atividade proposta, sendo que, esses fizeram a leitura de suas respostas para que todos os colegas da turma aprendessem as respostas corretas. Na relação das respostas a pergunta discursiva, na turma de 20 alunos, notou-se que $85 \%$ dos alunos acreditam que a 
água é um recurso que pode se esgotar e $15 \%$ acreditam que é um recurso infinito, conforme mostrado na Figura 5.

"A água potável no mundo irá acabar?"

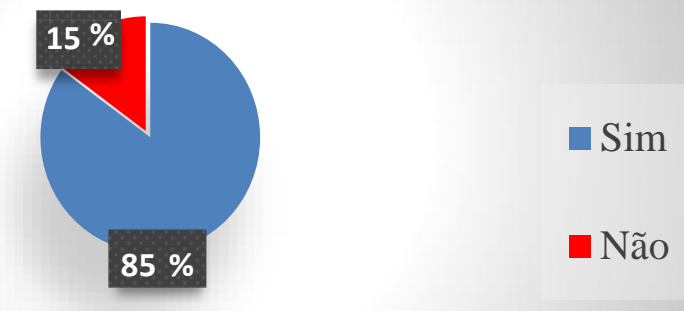

Figura 5 - Percentual das respostas dos 20 estudantes a pergunta "A água potável no mundo irá acabar?", na Escola Municipal Tenda dos Morenos, turma de $7^{\circ}$ ano.

\subsection{Palestra para a turma de $8^{\circ}$ e $9^{\circ}$ ano}

$\mathrm{Na}$ turma formada pelo $8^{\circ}$ e $9^{\circ}$ anos, sobre os questionamentos iniciais, notou-se que os alunos sabiam sobre os assuntos relacionados à água, como sua importância e as formas de economizá-la. Porém, mesmo tendo essa consciência, notou-se que muitos não estavam sensibilizados com a questão da água, visto que, houve relatos de alunos que disseram tomar banhos demorados com o chuveiro ligado durante todo o banho, que ao ensaboar as louças deixam a torneira aberta. Dessa forma, foi possível dar um enfoque sobre as ações cotidianas necessárias para economizar água. Então, procurou-se mostrar o quanto de água era desperdiçado enquanto se fazia essa ação, dando continuidade para a amostragem de desperdício de água em outras atividades cotidianas.

$\mathrm{Na}$ atividade de perguntas e respostas, quatro alunos se destacaram com bom desempenho. Na relação das respostas à pergunta discursiva, na turma de 27 alunos, notou-se que $74 \%$ dos alunos acreditam que a água é um recurso que pode se esgotar e $26 \%$ acreditam que é um recurso inesgotável, os dados podem ser visualizados na Figura 6.

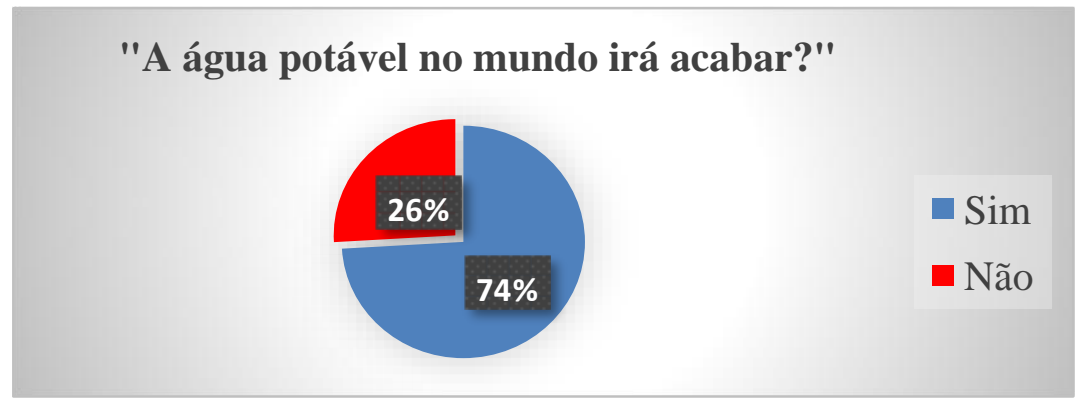

Figura 6 - Percentual das respostas dos 27 estudantes a pergunta "A água potável no mundo irá acabar?", na Escola Municipal Tenda dos Morenos, turma de $8^{\circ}$ e $9^{\circ}$ anos.

$\mathrm{Na}$ atividade prática, ao questionar sobre a água contaminada com terra vermelha, rapidamente os alunos disseram que ela estava imprópria para o consumo. Restando apenas a água limpa e a água com vinagre, pediu-se para que opinassem quanto ao que eles achavam sobre aquelas duas amostras de água, apenas pelo aspecto visual todos responderam que 

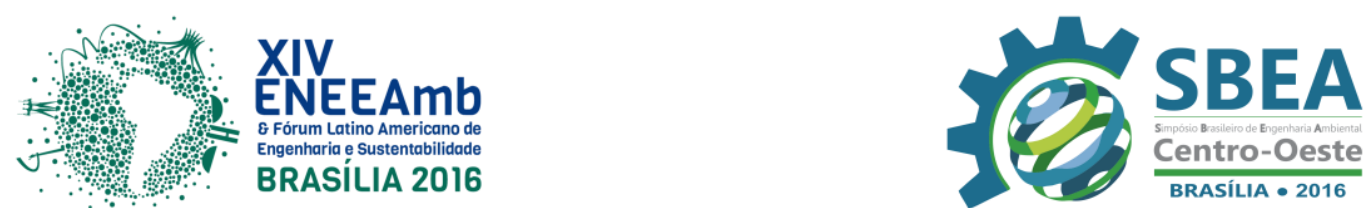

poderiam consumir, pois ambas estavam transparentes. Foi então solicitado que os alunos voluntários cheirassem as amostras de água. Um dos alunos percebeu que não havia cheiro, o outro sentiu o cheiro do vinagre, assustando-se e promovendo a curiosidade dos outros colegas de sala. Logo, foi ressaltado que não devemos acreditar que a água está própria para o consumo apenas observando se ela está transparente.

Comparando os resultados obtidos nas quatro palestras, apenas as turmas de $4^{\circ}$ ao $6^{\circ}$ ano apontaram que a água do mundo "talvez" pode acabar ressaltando que tal situação só depende das ações do homem.

\section{CONSIDERAÇÕES FINAIS}

$\mathrm{Na}$ educação ambiental realizada na Escola Municipal Tenda dos Morenos se ressaltou a conscientização dos alunos quanto à contaminação e o uso inapropriado da água nos diversos setores. Dentre todas as series analisadas, as que possuíram um debate mais profundo foi a turma de $6^{\circ}$ ano, visto que se mostraram participativos nas atividades e curiosos sobre a questão das doenças vinculadas a água, sendo que ocorreram relatos sobre a dengue por parte dos alunos. Em contrapartida, o $7^{\circ}$ e $9^{\circ}$ ano se mostrou defasado no início do minicurso, demostrando pouca empolgação durante as discussões sobre o tema, em função se ser o último horário de aula do dia. Além disso, no momento da atividade de perguntas no $6^{\mathrm{o}}$ ano, os alunos demonstraram bastante interesse e empenho em responder corretamente.

Os minicursos realizados ao longo das séries trabalhadas promoveram uma agregação dos conhecimentos científicos adquiridos nas aulas com os conhecimentos do senso comum que os alunos detinham.

\section{Agradecimentos}

Os autores agradecem aos órgãos de fomento FAPEMIG (processos números: APQ- 02249-14 e APQ-03219-14), CNPq, Rede Mineira pelos auxílios financeiros e bolsas concedidas (APQ-03219-14).

\section{REFERÊNCIAS E CITAÇÕES}

\section{AGÊNCIA NACIONAL DE ÁGUAS (ANA). O Uso Racional da Água. 2015}

BRASIL - Secretaria de Educação Fundamental. Parâmetros curriculares nacionais: meio ambiente e saúde. Brasília: 128 p, 1997.

CUBA, M. A. Educação Ambiental nas escolas. ECCOM, v. 1, n. 2, p. 23-31, 2010.

FREITAS, N. T. A.; MARIN, F. A. D. G. educação ambiental e água: concepções e práticas educativas em escolas municipais. Nuances: estudos sobre Educação, v. 26, número especial 1, p. 234-253, 2015.

GRASSI, M. T. As águas do planeta terra. Cadernos Temáticos de Química Nova na Escola, Edição especial, p. 31-40, 2001. 